\title{
Peculiarities of Business Presentation Communicative Means
}

\author{
Svetlana Burikova ${ }^{1}$, Marina Kuznetsova ${ }^{1} \&$ Ekaterina Ovchinnikova ${ }^{1}$ \\ ${ }^{1}$ Peoples' Friendship University of Russia (RUDN University), Moscow, Russia \\ Correspondence: Svetlana Burikova, Faculty of Economics, Peoples' Friendship University of Russia (RUDN \\ University), 117198, 6 Miklukho-Maklay Str. Moscow, Russia. E-mail: burikova_sa@pfur.ru
}

Received: June 16, 2020 Accepted: July 23, $2020 \quad$ Online Published: July 30, 2020

doi:10.5539/ijel.v10n5p311 URL: https://doi.org/10.5539/ijel.v10n5p311

\begin{abstract}
This article, deals with the particularities of business communication considering them from the two main perspectives: linguistic and extra linguistic.

It focuses on the factors, features, cultural peculiarities, goals and means, principles, ethical norms and strategies of business communication. The article highlights, cultural aspects, psychological features, interlocutors-intentions and ethical norms that define the shape, style, and content of a business message.

After a presentation of transcript analysis, undertaken with the methods of contextual and lexical analysis, the authors provide a rhetorical criticism of the communicative means - linguistic and extra linguistic — of a business presentation as part of business communication.

In conclusion, the authors determine that business presentation strategies, despite being typical, may be applied with peculiar linguistic means, lexical or grammatical, and various speech acts in accordance with the communicative aim.
\end{abstract}

Keywords: business communication, means of communication, discourse, communicative strategies

\section{Introduction}

\subsection{The Statement of Problem}

The intensification and speed of integrity processes around the world is the key feature of the information era. Due to the surge in technological and social achievements and modifications, there are far more communication opportunities than previously available.

Enjoying the benefits of the global market and freedom of information, businesses can create promising links on the national and international scales, building interaction with the use of communication.

Business presentation is one form of communication currently gaining popularity, because it is an effective tool for conveying the messages to different interlocutors, and, consequently, achieving numerous professional goals. Because a presentation is part of any business communication, it is important now to research the means of message delivery to a listener.

Many studies have been conducted on business discourse and communication. "Linguistic and Socio-Cultural Peculiarities of Business Communication" (2011) of Course Paper focuses on formal and non-formal, verbal and non-verbal interaction.

Swathi in his paper "The Importance of Effective Presentation for Organizational Success" (2015) claims: "Presentations are important to a company or an organization because good presentations improve communications within the company, which improves morale and reduces stress. Miscommunication is very expensive for a company and misunderstandings waste time. It clarifies the company's policy and improves the chances of selling the product or an idea. Thus, organizations are judged on their presentations. The elements of dynamic delivery include body language (55\%), content $(7 \%)$ and voice $(38 \%)$.

As we have set a practical significance of our paper to implement the findings in the education business discourse, we have to mention the work of Yeonkwon Jung "Trends in Business Communication Research, Teaching, and Academic Societies in Korean Higher Education" (2018).

Psychologist Jeff Goins stated that, "people do judge a book by its cover, so the best thing to do is to write a good book and design a good cover for it". Through this metaphor, Goins means that, the intention behind a 
subject's speech will better meet goal, when there is a suitable "cover" provided by strategies, methods, and tools.

Presentation is a special form of organizing information that is designed for a specific audience. Having analyzed the presentations we can assume, that the effectiveness of a presentation depends on the strategy, tactics, and methods of its delivery. And, the presenter can combine all the means of presentation delivery according to the communicative aim.

Within this research, the following tasks are to be completed: - to review the types and typical features of a business presentation along with its delivery methods; - to research into the strategies corresponding to each of the presentation type and reveal how they impact the audience; - to conduct an analysis of recently delivered business speeches of different types using the theoretical basis.

This study deserves attention because of analyzes of the up-to-date business presentation speeches which have never been done from perspectives of pragmatic and rhetoric along with the language units corresponding to them.

This study may be used in institutions of higher education while teaching linguistics, pragmatics and business discourse, and in staff training sessions dedicated to communication skills and making of speech.

\subsection{Literature Review}

The works of the linguists such as Austin (How To Do Things With Words, 1955), Van Dijk, Searle (Speech Acts, 1969, What is Speech Act, 1986), Van Dijk (Critical discource analysis, 2001, Macrostructures: An interdisciplinary study of global structures in discourse, interaction, and cognition, 2019) are dealing with speech theory and discourse analysis.

Faerch and Kasper Faerch (1983), "Strategies in Interlanguage Communication" are widely sited within the framework of the issue. Canal and Swain have developed The Theory of Communicative Competence (1980).

Jeannette Littlemore has elaborated on the issue in "The communicative effectiveness of different types of communication strategy" (2003),

Beebe and Beebe (Public Speaking: An Audience Centered Approach, 2008) etc. have been devoted to the study of the issue.

David Crystal, as well as Yulia Danyushina have investigated the business discourse, which is strongly connected to the notion of business presentation. Bargiela-Chiappini unites both terms-business communication and business discourse defining the latter as everything connected with the way people communicate with each other.

Many scholars in the linguistics and pedagogy area, such as Bachman, Canale and Swain, reveal the fact that communication strategy is closely connected with the other notion-communicative competence. It stands to reason, to carry a message by linguistic means, orally or in a written form, a message producer should possess the ability to use these means in an appropriate and effective way. It can be done through acquisition and development of a number of language skills.

In Canale and Swain's theory of linguistic competence, these skills are as follows: grammatical competence, including vocabulary, morphology, syntax and grammar; discourse competence suggesting the unity of the oral or written text (coherence and cohesion); sociolinguistic competence which is interpreted as the understanding of social and cultural context, and, finally, strategic competence embracing verbal and non-verbal strategies. (Peterwagner, 2005, p. 12). All the components are interrelated.

Apart from Canale and Swain's framework of linguistic competence, there are several later classifications which generally follow the same logic, but the interpretation and sets of elements included are different. For example, according to Bachman's conception, there are two sides to linguistic competence: organizational, in charge of grammatical accuracy and text unity, and pragmatic one, split into illocutionary (including manipulative, imaginative and other linked functions) and sociolinguistic competences.

The definition of pragmatic competence formulated by Bachman claims: “(..) the mental capacity for implementing the components of language competence in contextualized communicative language use" (Bachman, 1990, pp. 84, 87)

Many researchers attempt to study and explain the principles which a successful communication is based on. Their findings can be equally applied to the business interaction as any kind of communication follows the same logic: information exchange, the speaker goal and mutual understanding. We have to mention the essence of 
pragmatics and the principles of cooperation, mentioned by Attardo.

The great contribution to the development of pragmatics as an independent discipline within linguistics is made by Grice. He is the author of the Cooperative Principle containing four maxims (Hadi, 2013, pp. 69-70). His maxims are aimed at building appropriate formal communication, either scientific or business. They are as follows: 1) Maxim of quality 2) Maxim of quantity 3) Maxim of relation 4) Manner. Speaker is expected to be laconic, avoids ambiguity or obscurity, the message is characterized by directness.

Grice believes that there is high compatibility and harmony among all the four maxims, therefore the more of them are applied in communication the higher its efficiency is. Indeed, it seems apparent that the maxim of manner contributes to the application of quality maxim (no ambiguity, straightforwardness $=>$ adequacy); maxim of quantity ensures that a speaker can be understood by hearers of different communicative competence levels (no excessive words or phrases $=>$ no confusion).

However, there is no agreement among researchers on how to interpret the cooperation meaning. Many scholars believe that Grice meant it to be successful interaction in which both participants strive towards understanding and progress guided by universal rules which facilitate and accelerate the process. But Hadi argues that such an approach does not take account of highly complicated human nature and interpersonal factor (Hadi, 2013).

Gibson attaches great importance to non-verbal communication in business environment all around the world (2000, pp. 28-30). He starts with the dress which should be chosen appropriately with cultural diversity, formality/informality, corporate culture and individual partner's features taken into account.

The significant role also belongs to Edward Hall's ideas concerning cultural difference in the use of communication means. He introduces such notions as high-context and low-context communication suggesting that people may fall back on tools other than words and literal meaning while formulating a message and the way they express they ideas depends on cultural diversity (1976, pp. 105-116).

According to the purposes of presentation and the context (audience, place, time etc.), its speech can be of certain specification and structure. Tulchinsky enumerates them as follows (2010, pp. 86-88): 1) Informative speech. 2) Persuasive speech 3) Special speech. This study will be based on this classification.

\subsection{Hypotheses and Research Design}

Within the study, main factors constituting the context of message exchange have been reviewed: we have noticed that cultural aspect, psychological features, interlocutors' intentions and ethical norms define the shape, style and content of a business message. However, regardless topic and context of interaction, communication suggests collaboration and attempt to reach agreement and mutual understanding. Therefore, we should consider the cooperation principle as fundamental regulations or a set of recommendations, a necessity to bear in mind the common rules. At the same time, interlocutors should be flexible, be able to adjust their, message to the context of communication and facilitate it, applied separately or in various combinations, if necessary. Conducting speeches analyzes, we will pursue the idea of flexible usage of strategies and tools when delivering a presentation.

\section{Method}

\subsection{Procedure}

This study considers the notion in a narrow meaning as the focus is on the business communication. It provides the analyzes of the up-to-date business presentations - speeches - which have been done from perspectives of pragmatic and rhetorical strategies review-along with the appropriate language. A detailed analysis of one speech selected will illustrate the conducted research.

Firstly, we considered the notion of communication strategy and communication tactics proposed by different researches, subsequently studied the classification of strategies. Secondly, we investigated the peculiarities of business communication and its context, and different factors which impact the process of professional interaction. Further, we reviewed the types and typical features of business presentation along with its delivery methods. Finally, we researched into the strategies corresponding to each of the presentation type and reveal their impaction on the audience.

\subsection{Study Materials}

This study has been conducted on the materials of three speech transcripts published in 2016-2017, representing the presentations in business context given by top management of companies. The speeches were selected from the websites: www.nestle.com, theweco.com, bweconomicforum.com. The three different types of speeches (informative and persuasive, and a speech for special purposes) have been selected for detailed analyzes. The 
results of the first two were tested in the conferences (SGEM, 2018; RUDN, 2018). The analysis of the speech for special purpose will be provided in this article.

For analyzing the materials the following methods are used: - contextual analysis as a method of studying text and its cultural, social, or political context;

- conversation analysis as a specific form of investigation or enquiry; It is when a conversation refers two or more individuals talking with one another just for the sake of talking. It is a form of sociability and reflects an individual's ability and willingness to interact with others. At a basic level, conversation analysis is viewed as the study of talk. In a broad sense, conversation analysis could refer to the study of people talking together, oral communication or even study of language use.

- rhetorical criticism as it analyzes the symbolic artifacts of discourse - the words, phrases, images, gestures, performances, texts, films, etc. that people use to communicate; Rhetorical analysis shows how the artifacts work, how well they work, and how the artifacts, as discourse, inform and instruct, entertain and arouse, and convince and persuade the audience; as such, discourse includes the possibility of morally improving the reader, the viewer, and the listener. Rhetorical criticism studies and analyzes the purpose of the words, sights, and sounds that are the symbolic artifacts used for communications among people (Wikipedia).

\section{Results and Discussion}

After we have thoroughly studied the great amount of theoretical resources on the topic, we are going to undertake an analysis of a business presentation to reveal what means could be used to achieve a business communicative goal. It is known, that the formats of presentations are oral, multimedia, PowerPoint, short impromptu and long-planned.

As we have mentioned before, the materials of this study could be used while teaching linguistics, pragmatics and business discourse; also, in training communication skills and making of speech. That is why, we are going to present a detailed speech analysis, in particular, of a speech for special occasion.

There are different speech strategies for informative and persuasive speeches. As far as the first type is concerned, the strategies are to simplify the most difficult parts of speech in order to make them easier to understand and memorize (e.g., analogies, description, classifications) or to grab the listeners' attention (e.g., story-telling, audience-centered approach etc.). The second group gathers the strategies used to persuade the public. It can be effectuated in two ways: providing reasoning supported with facts and argumentation (influencing the logic-logos) or appealing to emotions, feeling etc. (ethos, pathos, motivation). However, if the topic and the goal require so, a speaker may combine both approaches.

A special speech is given on specific occasion, characterized by a relatively short length, emotional message reflecting individual traits of speaker's style. Such speech should not contain any ambiguous or questionable statements but in some cases should be aimed at evoking a certain reaction, emotional respond.

For instance, an introductory (or ceremonial) speech may be designed to welcome, greet the audience before starting a presentation or a report, introducing the participants of discussion and special quests, express thanks to the organizers or an event, sponsors and partners. Also, it may be a final point of a big information or convincing speech, thanking the audience for their attention, etc.

Notwithstanding what the character, the type of the presentation is, there are common principles and logic, order of speaker's actions. It includes the following stages: preparation, research, speech making and, eventually, speech production. The first three represent the constituents of the speech planning process while the last refers to the presentation being an outcome of all the preceding work.

To illustrate the theoretical basis done before, we now are going to consider the speech analysis of "The Address by Peter Brabeck-Letmathe at the General meeting of Nestle" on the subject of the linguistic and extra linguistic means of business presentation and the communicative impact reached.

\subsection{Speech Overview}

The speech of the Nestle Board Chairman Peter Brabeck-Letmathe was on the 6th of April, 2017 at the annual general meeting for specific occasion - 150th Anniversary of the company. Therefore, it is not designed for large public, but for Nestle shareholders, the board of directors and senior managers. The address provides the resume of the company's long-term performance, achievements, the review of current situation as well as outlook for the future. Let us now consider the main points more closely.

In the first part of his speech Brabeck-Letmathe notices the symbolic character of the year 2016 as the 150th 
Anniversary. He makes a conclusion about the outcomes of the year by saying that despite the fact there were many economical challenges and volatility, Nestle continues following its way standing by its mission and views and overcomes difficulties.

The significant part of the speech is dedicated to the global problems of humanity: poverty and its specific attributes, such as poverty and malnutrition. Although there have been positive changes in struggling with them, there is more to be done henceforth. The speaker assures the audience that Nestle is already making its great contribution by funding science, conducting food research, permanently strives to increase the quality of the products and will continue doing so because the future brings new challenges. According to Brabeck-Letmathe, the company possesses resources and has accumulated potential enough for stable growth in the years to come.

Moreover, the speaker expresses his gratitude to the company staff, managers and inferior employees for their joint efforts, enthusiasm and high qualification.

Addressing the shareholders, he thanks them for the loyalty towards Nestle; then, he highlights that the company has been gradually increasing the dividends for over 20 years which is the reward for their trust and optimistic long-term vision.

The table below demonstrates the embodiment of the classical organizing of a speech, implemented by Brabeck-Letmathe (Table 1).

Table 1. Presentation structure

\begin{tabular}{lll}
\hline Introduction & Main body & Conclusion \\
\hline Company's performance & Current situation & Outlook for the future \\
\hline
\end{tabular}

\subsection{Strategies Review}

To begin with, it is very important to pay attention to the fact that Brabeck-Letmathe refers to the past, the present and the future, speaking about company's history, actual state of affairs and the forecast for future performance correspondingly. In order to consider strategies which he uses, we will fall back upon this logic, dividing the ideas by defining whether they belong to the past, the present or the future. Furthermore, the speaker draws connection between past and present which puts the stress on reliability, long-term prosperity of Nestle as well as dedication to mission and traditions. That is to say, we should also study the strategies which express such connections. The table below presents the strategies review (Table 2).

Table 2. Presentation strategies

\begin{tabular}{lll}
\hline & Strategies & Tools \\
\hline Past & company's history & sequence of sentences united with repetition \\
Present & actual state & issues of the company $=>$ issues of the industry => economy issues => global issues \\
Future & future performance & forecast, supporting this with numbers \\
\hline
\end{tabular}

1) Past:

- 150th anniversary of the company was celebrated last year: “(...) 2016 marked the 150th anniversary of the founding of Nestlé".

- 2016 was not only symbolic because of that but also was the year of important events: “(...) appointment of Ulf Mark Schneider as Group CEO”; “(...) company achieved strong operating and financial result”. Then, Brabeck-Letmathe highlights that it was in spite of numerous challenges, such as negative economic trends: "They were achieved in a difficult and volatile economic and political environment in many parts of the world and in a deflationary environment in Western Europe".

- He uses those outcomes so as to connect the present with the past and assures shareholders that Nestle continues all its activities and is still developing, devoted to the initial principles: "Today, we are still driven by the same spirit of innovation, quality and excellence as our founders"; "We are still guided by our values"; "We are still driven by our purpose". It should be noticed, that all the three above-mentioned quotes constitute the sequence of sentences united with repetition ("We are still") which serves as the emphasis.

- In addition, the speaker says that the performance of 2016 proves his statement about company's reliability and also refers to the future: "These results are further evidence of (...) resilience and (...) ability to adapt and grow 


\section{(...) while preparing for the future."}

- Positive motivation is used as the means of superior and inferior staff encouragement: "I should like to pay tribute to the fine work of our management team (...) "; “ (...) express my appreciation to Paul Bulcke for his leadership of Nestlé"; "commend the hard work and dedication of the 328000 Nestlé employees all over the world".

- As the Board chairman proposes the shareholders the increase of dividend rate, he emphasizes that the company is worth trusting in present and future as it has always paid the dividend which has been gradually increased. Thus, he refers to the past in order to provide the facts (figures) and, therefore, relies on logos: "Since 1942 your company has never cut the dividend (...)." "For the last 21 years (...) the dividend paid out has increased every year."

2) Present:

- The speaker describes the current situation and issues of big importance. This is where we find the appliance of inductive reasoning, since the enumeration starts with the specific problems and switches to some existing on a large scale. In other words, there is the following logic: "issues of the company $\Rightarrow$ issues of the industry $=>$ economy issues => global issues". This becomes apparent as we consider the examples. First, the company scale: "Consumer expectations of Nestlé are changing dramatically”. Second, the industry scale: “(...) our sector is at a turning point in its history". Then they are followed by the concerns about the state of world economy: "Economic activity, free trade and international trade (...) are now under threat." Moreover, he touches upon social issues, such as poverty and malnutrition: “(...) globally, one person in three is malnourished today.”. Finally, the summarizing statement, true for all the aforementioned, is introduced: "We live in times of profound change, turbulence and uncertainty.";

- On the one hand, Brabeck-Letmathe addresses the past to show that many of the current problems have their sources in the history: "Throughout history, one of the great challenges (...) has been to ensure sufficient food for its survival and development." On the other hand, he stresses that some of those processes continue and the other ones are becoming worse: "We are seeing the rise of populist tides", "Our societies are facing profound changes and a complete transformation of economic models". Altogether his statements quoted above contain the appeal to the sense of duty, responsibility and universal human values.

- The speaker claims that there is a necessity to take measures in order to prevent further spread and exacerbation of negative tendencies. Despite the fact that some steps have already been taken, it is insufficient to fight the global problems: "despite some remarkable progress, much remains to be done to eradicate poverty, the dual burden of over- and under-nutrition and thus further improve the health of vulnerable populations." Subsequently, he refers to an authoritative global organization and expresses the company's agreement with its view on the issues. In addition, he connects the present and the future by referring to the long-term strategy: "This is clearly part of the United Nations sustainable development goals up to 2030, which we fully subscribe to and actively contribute to";

-To support the previous idea, Brabeck-Letmathe provides the audience with facts, precising what contribution the company makes in favor of the international community and gives reasons for such activities: "We are investing in science and innovation (...). We are innovating to provide personalized nutrition solutions that allow better health management, and even the prevention or cure of certain diseases." "We continue to adapt our products and historical brands so that they actively contribute to a healthy and happy life for our consumers";

3) Future:

- Touching upon the topic of economic challenges, the speaker not only mentions those of the past and reviews those of the present but, what's more, makes a forecast, supporting this with numbers: "by 2030, the rapid growth of the world's population (...) will boost demand for food by $35 \%,(\ldots)$. More than two-thirds of the world's population will live in urban areas by 2050.";

- He also emphasizes the ambiguity of changes which may bring benefits and but are not free of risks: "We are on the eve of a 'fourth industrial revolution', (...) full of challenges, but above all full of great opportunities. The connection between the present and the future is also apparent when the speaker gives estimation of Nestle potential which justifies optimistic expectations and assures the shareholders of the company's reliability: "Nestlé has the human, technological and financial capabilities to continue to grow and create value, both for you, our shareholders, and for society at large". Moreover, he gives the credit to the staff as the people who have gained that potential and will continue doing so: "All Nestlé employees will know how to drive your company to the results you (...) expect. Leaving Nestlé with such extraordinary human capital is what I am most proud of." 


\subsection{Language Review}

The great amounts of adjectives with positive meaning is used to express gratitude or commend the performance of the company: "strong (...) results»; "fine work"; "extraordinary human capital". The adjectives with negative meaning refer to the current challenges on small and large scale: "malnourished"; "difficult and volatile (...) environment".

Besides the nouns which represent processes and trends, such as "change, turbulence and uncertainty", there are many which mean the strengths of Nestle in general and its staff in particular, and its activities: "resilience"; "skills and knowledge"; "efficiency", "quality"; "innovation"; "research", etc.

The speaker also falls back on numerous emotion-arousing words, both nouns and word groups like "adjective + noun" or "noun + noun": "success", "spirit", "enormous opportunities"; "the honor and the pleasure"; "wonderful company"; passion. Those words express speaker's dedication to the company, admiration towards the staff and gratitude to the shareholders.

As far as verbs are concerned, they are used in numerous tenses, including Present Simple, Present Continuous, Present Perfect, Past Simple, Future Simple. The verbs in tenses of Present dominate. Present Simple is used: 1) to describe company's and employees` features which are true nowadays: "Nestlé has the human, technological and financial capabilities"; “(...) we have the skills and knowledge (...)”; Today, we are still driven by the same spirit (...)"; 2) To consider characteristics and provide definition for some phenomena: "(...) malnutrition manifests itself in a lack of calories(...). "...translates into an over-consumption of calories"; 3 ) to introduce modal verbs so as to show the importance of emerging changes and necessity of measures to take: "food production must above all offer..."; 4) To address the audience: "I would like to sincerely thank (...)"; 5) To make an offer to the shareholders: "the Board of Directors once again proposes an increase...".

Present Perfect is used to consider the outcome of company's activity and features of its performance over a certain period of time: "We have indeed continued to invest..."; "Since 1942 your company has never cut the dividend..."; "Nestlé employees have made (...) a difference...". Although, in several cases it refers to permanent phenomena in the world history: "( $\ldots)$ one of the great challenges facing humanity has been to ensure sufficient food..."; "this has already become the most pressing public health problem". Present Continuous verb forms serve to enumerate changes in process or measures currently taken by Nestle: "We are seeing the rise of populist tides"; "We are innovating (...)"; "We are rapidly adopting new technologies (...)";

The Past Simple is the only past tense that we find in the transcript. It refers mainly to the results of 2016 and company's past: "2016 was also a crucial year (...)"; "2016 marked the 150th anniversary"; "They (the results) were achieved in a difficult (...) environment".

Finally, we notice frequent use of Future Simple in the sentences being predictions, expression of optimistic outlook etc.: "(...) the notion of nutritional security will be paramount.”; “(...) all Nestlé employees will know how to drive your company (...)". The speaker also uses the 1st Conditional so as to make a proposal: "If you accept this proposal, the total amount of the dividend paid to shareholders will come".

The modal verb "must" supports the idea of the necessity of active participation in facing global challenges and set the specific goal: "(...) food production must above all offer better nutritional quality".

Apart from numerous constative verbs there are also various performatives which constitute the core of several speech acts throughout the address: 1) Commissives: "the Board of Directors once again proposes an increase to CHF 2.30 per share." 2) Expositives show chairman's approval of employees' work or gratitude towards shareholders, the agreement with the UN position: "the United Nations sustainable development goals up to 2030, which we fully subscribe to (...)"; "I should like to pay tribute to the fine work (...)"; "Executive Board value your trust in them"; 3) Verdictive representing an appraisal, opinion: "We are confident that we have the skills and knowledge"; "It is therefore increasingly recognized that sufficient food production is no guarantee of food security".

Another feature is the use of adverbs supporting the idea of spreading trends, transformations, changes in progress, moving forward together with verbs: "further", "dramatically"; "increasingly"; "more and more"; "rapidly".

Furthermore, we should take into account what personal and possessive pronouns are there in the speech since they are also the part of strategy: 1) the first person: I /my-the speaker addresses the audience on behalf of himself so as to thank, praise etc. this is the means of establishing direct contact: "I would like to express my appreciation (...)"; "I express my full confidence (...)"; "I sincerely appreciate it." We/our-by saying "we", the chairman suggests "Nestle" including staff, managers, the Board and shareholders: "We have just celebrated 
(...)"; "We are rapidly adopting (...)". This is a typical example of audience-centered strategy. Apart from that, another meaning of "we" which we can find in the speech is "global community; humanity". Such interpretation of the pronoun highlights that the existing issues can't be ignored by anyone, so Nestle is also concerned about them. The same goes for the possessive "our": "Our societies are facing profound changes (...)". "We live in times of profound change (...)"; 2) You/your: Brabeck-Letmathe also uses the pronoun "you" suggesting "shareholders" so as to make the address more personal and specific; it helps to emphasize to what extent he values the listeners: “(..$)$ you have shown me your support and confidence.”; “(..$)$ we create value for you, our shareholders". The possessive "your" expresses the idea of coinciding purposes and shared values, as the company equally belongs to staff and shareholders: "your company achieved (...)"; “(..) you have shown me your support and confidence".

Apart from particular words we should also consider a number of peculiarities at the syntactical level. For instance, the speaker uses emphatic structures in order to support his argumentation: "It is against this backdrop that the future of our company will be written."; "This is what Nestlé calls creating shared value."

Finally, we notice several repetitions at the level of a sentence and at the level of a text. For instance, there is a sequence of three sentences which can be considered as a macro speech act carrying the idea of devotion to the basic principles of company's activity and stability. It starts with the same structure "Personal pronoun + verb + adverb + verb" (two verbs are the parts of passive form): "Today, we are still driven by the same spirit of innovation (...)"; We are still guided by our values (...). We are still driven by our purpose (...)". If considered separately, the sentences are nothing more but descriptive. Taken together they convey the above-mentioned idea supported with repetition as the emphasis mean.

One particular structure is not just repeated in a sequence but is found in separate sentences in different passages: "Against this backdrop and despite some remarkable progress (...)"; "It is against this backdrop that the future of our company will be written." Such repetition establishes logical connection between different parts of speech which state and develop similar ideas and, therefore, contributes to coherence.

The example showing repetition at the sentence level presents the structure "verb + adverb" reproduced three times within an utterance (although the verbs are different): "To innovate better, to increase efficiency, to communicate better and to better interact with the world around us." Other sentences comprise the same verb in different Tenses: "Growth is and will remain the best way $(\ldots)$ "; "(..) we are seeing more and more consolidation (...)". All these cases of repetition represent various forms of emphasis.

The speech is an address of the Board Chairman to the shareholders and managers of the company. Along with inductive reasoning and facts (logos) when mentioning global problems the speaker falls back on the appeal to different senses (pathos). Thus, this is a speech for special occasion containing persuasive elements. The combination of different tenses allows him to speak about company history, actual performance and the forecast for the future of Nestle as well as the past, present and future of humanity, report about results and give the credit to company staff. The table below shows the tools implemented to reach the communicative goal (Table 3 ).

Table 3. Intentions and tools of a speech for special occasion

\begin{tabular}{|c|c|c|c|c|c|c|c|}
\hline \multicolumn{8}{|c|}{ TOOLS AND INTENTIONS } \\
\hline $\begin{array}{l}\text { Evaluative } \\
\text { adjectives }\end{array}$ & Nouns & $\begin{array}{l}\text { Emotion } \\
\text {-arousing words }\end{array}$ & Numerous tenses & $\begin{array}{l}\text { Numerous } \\
\text { constative } \\
\text { verbs }\end{array}$ & Adverbs & Syntax & $\begin{array}{l}\text { Personal and } \\
\text { possessive } \\
\text { pronouns }\end{array}$ \\
\hline $\begin{array}{l}\text { to express } \\
\text { gratitude or } \\
\text { commend the } \\
\text { performance }\end{array}$ & $\begin{array}{l}\text { to represent } \\
\text { processes and } \\
\text { trends }\end{array}$ & $\begin{array}{l}\text { to express } \\
\text { dedication to the } \\
\text { company }\end{array}$ & $\begin{array}{l}\text { To describe features; } \\
\text { to consider } \\
\text { characteristics; } \\
\text { to address the } \\
\text { audience; } \\
\text { to make an offer }\end{array}$ & $\begin{array}{l}\text { to } \\
\text { constitute } \\
\text { the core } \\
\text { of speech } \\
\text { acts }\end{array}$ & $\begin{array}{l}\text { to support the } \\
\text { idea of trends: } \\
\text { transformations, } \\
\text { change, } \\
\text { progress }\end{array}$ & $\begin{array}{l}\text { to express } \\
\text { the idea } \\
\text { of } \\
\text { company's } \\
\text { activity and } \\
\text { stability }\end{array}$ & $\begin{array}{l}\text { to expresses the } \\
\text { idea of } \\
\text { coinciding } \\
\text { purposes and } \\
\text { shared values }\end{array}$ \\
\hline
\end{tabular}

\subsection{Strategies Implementation}

To achieve a communicative goal, the execution of strategies is to be used, which, in their turn, include many components dealing with specific problem, thus strategy is built with many appropriate tools. Such tools are named tactics. A speaker sets a communicative goal, and takes many steps executing a speech. Some of them are planned, some are chosen depending on current circumstances. The table below demonstrates the strategies to meet the communicative goal of a presentation. 
Table 4. Strategies for informative and persuasive speeches

\begin{tabular}{llll}
\hline Intention & Method & Tools & Result \\
\hline Inform & story-telling, audience-centered & analogies, description, classifications & understanding and memorization \\
Persuade & logos & ethos, pathos & motivation \\
\hline
\end{tabular}

\section{Conclusion}

This study was concerned with the peculiarities of business communication. Given that the phenomenon is very complex and numerous studies have been carried out before, we have addressed various theories and approaches to deal with it:

- The phenomenon of business communication has been studied from the two perspectives-linguistic and extra linguistic

- The analysis of presentation transcripts revealed peculiarities of the linguistic and extra linguistic means of delivering a business presentation as part of business communication.

The findings of the research are as follows:

The extra linguistic means of a business presentation are communication strategy and tactics.

- Communication strategy is a reflection of the message producer's intention. It is constituted with combination of linguistic means which, express the intention, produce the effect upon the recipient and, as a result, contribute to the speaker's communicative goal.

- Tactics represent specific stages of a strategy serving to achieve minor goals of communication.

- In addition to intention, communication context determines the content and delivery style of the message.

- Presentation sets a specific context within business communication. It represents a speech delivery in front of an audience. Depending on the communicative goals of presentation, the speech can be informative, persuasive or for special occasion.

- As we have deduced during the detailed speech analysis, although strategies are typical, they may be applied with different linguistic means, lexical or grammatical, and various speech acts.

- Despite the fact that there is division of presentation speeches into three categories with typical strategies, it doesn't mean that the speaker cannot combine several of them. All this is due to the great variety of topics, contexts of communication and individual speakers' styles.

- The results of multilevel speech analysis may be used for even more through consideration of the ways to express the intention of communication with specific linguistic units, rhetorical techniques of the impact on the recipient. Taking into account the permanently changing world and, consequently, the English language undergoing modification, the future will provide far more room for research.

\section{Acknowledgments}

The publication has been prepared with the support of the "RUDN University Program 5-100".

\section{References}

Androniki, K., \& Evgenia, B. (2014). Methodological Considerations for Qualitative Communication Research. Procedia-Social and Behavioral Sciences, 147, 544-549. https://doi.org/10.1016/j.sbspro.2014.07.156

Bachman, L. (2007). Fundamental considerations in language testing (pp. 84, 87).

Bargiela-Chiappini, F., \& Nickerson, C., (2007). Planken B., Business Discourse. Macmillan, 3-4. https://doi.org/10.1057/9780230627710_1

Bitsani, E. (2014). Methodological considerations for qualitative communication research.

Breeze, R. (2018). "Enemies of the people": Populist performances in the Daily Mail reporting of the Article 50 case. Discourse, Context \& Media, 25, 60-67. https://doi.org/10.1016/j.dcm.2018.03.008

Cause Paper. (2011). Linguistic and socio-cultural peculiarities of business communication. Retrieved from https://gendocs.ru/v10767/business_communication_linguistic_and_socio-cultural_peculiarities

Clarke, R. D. (Nov, 2005). Enjoy the silence: It has its place in effective communication. Black Enterprise. Retrieved from http://www.allbusiness.com/periodicals/article/843738-1.html

Danushyna, Y. V. (2010). Business discourse: the term, typology, analysis. News of VSPU. 
Dynel, M. (2009). Where Cooperation Meets Politeness: Revisiting Politeness Models in View of the Gricean Framework. Brno Studies in English, 35(1), 28.

Faerch, C., \& Kasper, G. (1983a). Strategies in Interlanguage Communication. London: Longman.

Gibson, R. (2000). Intercultural Business Communication (pp. 28-30, 43). Cornelsen \& Oxford University Press,

Hadi, A, (2013). A Critical Appraisal of Grice's Cooperative Principle. Open Journal of Modern Linguistics, 3(1), 69-72. https://doi.org/10.4236/ojml.2013.31008

Hall, E. (1976). Beyond Culture (pp. 17-24, 105-116). New York: Doubleday.

Hofstede, G. (1991). Cultures and Organizations (pp. 37, 96). London: McGraw Hill.

Kasper, G., \& Kellerman, E. (2014). Communication strategies: Psycholinguistic and sociolinguistic perspectives. New York: Routledge. https://doi.org/10.4324/9781315844350

Leech, J. (2005). Politeness: Is there an East-West Divide? Journal of Foreign Languages, 6(November), 12.

Littlemore, J. (2003). The communicative effectiveness of different types of communication strategy. Retrieved from https://scholar.google.ru/scholar?oi=bibs\&cluster=7621002126054247143\&btnI=1\&hl=ru

Maley, A. (2018). The teacher's sense of plausibility. Training Language and Culture, 2(1), 24-39. https://doi.org/10.29366/2018tlc.2.1.2

Malyuga, E. N., \& Tomalin, B. (2017). Communicative strategies and tactics of speech manipulation in intercultural business discourse. Training, Language and Culture, 1(1), 28-45. https://doi.org/10.29366/2017tlc.1.1.2

Peterwagner, R. (2005). What is the Matter with Communicative Competence (p. 12).

Radyuk, A. V. (2013). Cooperative communicative strategies and tactics as a means of harmonization of English business discourse (pp. 237-238). Bulletin of MGIMO University.

Spivak, V. A. (2002). Modern business communication (pp. 16-18, 27-28, 69-70). SPb.: Peter.

Stewart, R., Barsoux, J.-L., Ganter, H. D., \& Walgenbach, P. (1994). Managing in Britain and Germany (pp. 135-154). https://doi.org/10.1007/978-1-349-23584-1

Swathi, T. V. S. S. (2015). The Importance of Effective Presentation for Organizational Success. Retrieved from https://www.questia.com/library/p439509/iup-journal-of-soft-skills

Tulchinsky, G. (2010). Culture of business and political argumentation (pp. 86-87, 90-91). Textbook. Saint Petersburg: UTAS.

Van Dijk, T. A. (1985). Introduction: Discourse analysis as a new cross-discipline. Retrieved from http://www.discourses.org/OldArticles/Discourse\%20Analysis\%20as\%20a\%20new\%20Cross-Discipline.

Yeonkwon, J. (2018). Trends in Business Communication Research, Teaching, and Academic Societies in Korean Higher Education. Business Communication Research and Practice, 1(1), 26-32. https://doi.org/10.22682/bcrp.2018.1.1.26

Syda Productions. (2019). Conversation Analysis. Retrieved from https://www.communicationtheory.org/conversation-analysis/

https://en.wikibooks.org/wiki/Survey_of_Communication_Study/Chapter_7_-_Rhetorical_Criticism

\section{Copyrights}

Copyright for this article is retained by the author, with first publication rights granted to the journal.

This is an open-access article distributed under the terms and conditions of the Creative Commons Attribution license (http://creativecommons.org/licenses/by/4.0/). 